\section{Direct Compression by a Duodenal Diverticulum Causing Common Bile Duct Obstruction}

Duodenal diverticula have been implicated in the production of mild to severe biliopancreatic complications (1). A possible but rare event is extrinsic compression of the common bile duct by a juxtapapillary diverticulum. We report here the case of a 62-year-old man who presented with a longstanding history of intermittent dull pain in the right upper abdomen, partly accompanied by mild elevations of serum bilirubin, aspartate aminotransferase (AST) and alanine aminotransferase (ALT). On admission, bilirubin was 5.1 $\mathrm{mg} / \mathrm{dl}$, AST $126 \mathrm{IU} / \mathrm{l}$ and ALT $198 \mathrm{IU} / \mathrm{l}$. On endoscopic retrograde cholangiopancreatography, a juxtapapillary duodenal diverticulum causing extrinsic compression of the common bile duct was demonstrated (Figure 1). No debris in the diverticular lumen or cholelithiasis were found. A surgical approach was chosen, and during a six-month follow-up period, biliary obstruction and abdominal pain did not recur.

After the colon, the duodenum is the second most frequent site of diverticula in the digestive tract (2), and duodenal diverticula are reported with a variable frequency $(0.015-24 \%)$, the majority of them being localized in the second portion, frequently in close relation to the papilla. Although usually asymptomatic, duodenal diverticula may give rise to a variety of clinical syndromes, including biliary stasis. A diverticulum filled with debris may occasionally impair bile flow by direct extrinsic compression, as in the present case. The question of whether sphincterotomy might be of help in this particular setting remains unclear. In our patient, this uncertainty, and the absence of any surgical risk, led us to choose a surgical approach.

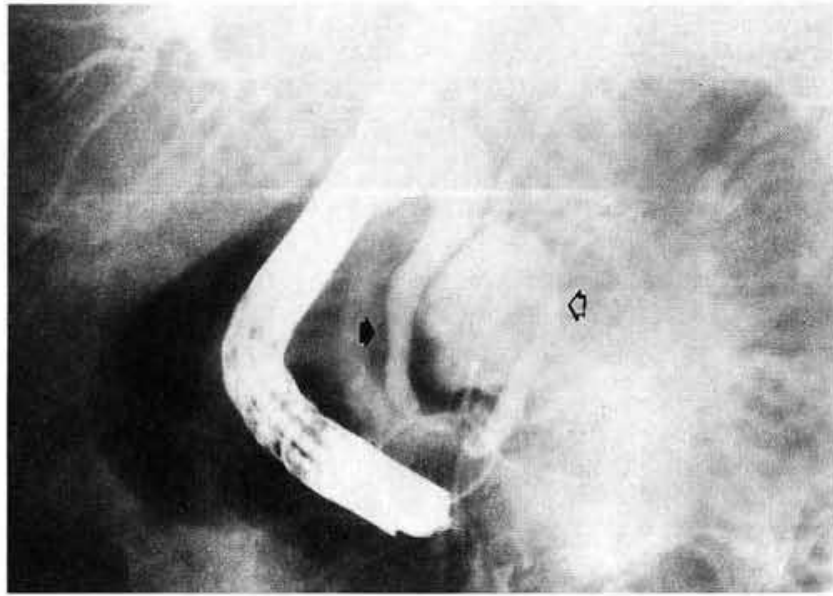

Figure 1: Endoscopic retrograde cholangiopancreatography showing extrinsic compression of the distal common bile duct (black arrow) by a juxtapapillary duodenal diverticulum (white arrow); the Wirsung's duct shows a normal configuration.

\section{A. L. San Román, V. F. Moreira, M. García, E. Merono, D. Boixeda}

V. F. Moreira, Ph. D.

San Martin de Porres 24, 1D

28935 Madrid, Spain

\section{References}

1. Lotveit T, Osnes M: Duodenal diverticula. Scand. J. Gastroenterol. 1984: 19: 579-581.

2. Dell' Osso A, Creti P, La Cava M, et al.: I diverticoli duodenali. Min. Med. 1986; $77: 469-478$. 